\title{
Small-Scale and Large-Scale Interventions to Improve [State] Students' Col- lege Readiness
}

\section{Dr. Virgil U. Pierce, University of Texas, Rio Grande Valley}

Dr. Virgil Pierce is an Associate Professor in the Department of Mathematics at the University of Texas Rio Grande Valley. His research is in mathematical and statistical physics, and involves the intersection of techniques from nonlinear waves, combinatorics, and random matrices. He works extensively on educational issues in high school and higher education, including the development of a College Prep Math course being used in public high schools in Cameron, Hidalgo, Willacy, and Starr Counties in Texas, and he has worked with a variety of issues surrounding entry level mathematics and science at two-year and four-year schools in Texas.

\section{Dr. Javier Angel Kypuros, University of Texas, Rio Grande Valley}

Javier Kypuros received a B.S.E. in Mechanical Engineering from Princeton University in 1996. He later received an M.S.E. and Ph.D. in Mechanical Engineering in 1998 and 2001 from The University of Texas at Austin. Javier began his career at The University of Texas at El Paso in 2001 and later joined the faculty at The University of Texas-Pan American (UTPA) in 2002. He is currently a Professor in the Mechanical Engineering Department and Associate Dean for Undergraduate Affairs in the College of Engineering and Computer Science. He was awarded Faculty Excellence Awards by the College of Engineering and Computer Science at UTPA for teaching in 2011 and service in 2012 and was recognized by the University of Texas System with a Regentss Outstanding Teaching Award in 2014. His research interests include Dynamic Systems and Controls, Bond Graphs, and Vehicle Systems.

\section{Dr. Shirley J. Mills, University of Texas, Rio Grande Valley}

Shirley J. Mills, Ph.D. graduated from the University of Nebraska-Lincoln in December 2005. She moved to Edinburg, Texas, to work at the University of Texas Pan American (UTPA) in 2007 and transitioned to the University of Texas Rio Grande Valley in 2015. She is a member of the Department of Organization and School Leadership and earned tenure and the rank of associate professor in 2012. In 2014 she was assigned to be the Interim Director of College Readiness Initiatives under the Vice President of Student Academic Success where she works with school districts, community colleges, Region One, and UTRGV officials to create a seamless transition for students moving from high school to higher education. 


\title{
Small-Scale and Large-Scale Interventions to Improve [State] Student's College Readiness
}

\author{
Virgil U. Pierce \\ School of Mathematical and Statistical Sciences \\ University of Texas Rio Grande Valley \\ virgil.pierce@utrgv.edu \\ Javier A. Kypuros \\ Department of Mechanical Engineering \\ University of Texas Rio Grande Valley \\ javier.kypuros@utrgv.edu \\ Shirley Mills \\ Department of Organization and School Leadership \\ University of Texas Rio Grande Valley \\ shirley.mills@utrgv.edu
}

\begin{abstract}
We are conducting two interventions aimed at improving entering students' college readiness and mathematics placement. The small scale intervention, A Bridge to Calculus, is intended to improve students' placement from College Algebra into Calculus 1. The target population for this effort are students with high school experience in a Calculus course but whose performance on placement exams does not reflect this experience. At our institution this is a significant number of students and the goal of the project is to develop methods to address and accelerate students in this category. The course design, to take advantage of the students' prior experience, emphasizes practice and mastery using a modified emporium course design and the ALEKS

software ${ }^{1}$. This intervention runs as a summer course to around twenty incoming students on our campus.

The large-scale intervention, A College Preparatory Mathematics Course, is a high school course developed for local high schools. Students who have completed the necessary coursework for high school graduation (Algebra 1, Algebra 2, and Geometry) but who have not achieved the Texas college readiness standard ${ }^{2}$ are targeted. The students in the course have had experience in their high school classes in all of the concepts in the state standard, but have not had the chance to practice and master the material. The course we have developed emphasizes practice and mastery like the small-scale one, but participating school districts could not afford the commercial software. Thus we have built a course around the WebWork software ${ }^{3}$ that is available through a free and open license. This paper is a description of the early results of these two efforts, and a description of the lessons learned in the efforts so far.
\end{abstract}

\section{Keywords}

College Readiness, Calculus Readiness, Mathematics Placement. 


\section{Introduction}

The University of Texas Rio Grande Valley (UTRGV) is a Hispanic serving institution in south Texas with two main campuses in Edinburg and Brownsville, Texas. The student population is predominately made up of students from the local region, which includes four of the poorest counties in Texas $^{4-7}$. The median incomes in the surrounding counties are significantly lower than those in the state as a whole ${ }^{4-7}$. Public school districts in the region are often underfunded, and are a mix of urban and rural districts. The university has a total enrollment of more than 27,000 students on two main campuses. Many students are first generation college students, and we find that accurate and effective mathematics placement is one of the biggest issues confronting students when they arrive as first-year students.

We are targeting two rather different groups of first-year students:

- Bridge to Calculus: one relatively small group has successfully finished high school with an unsuccessful experience in upper level mathematics (Calculus) from high school; and

- College Preparatory Mathematics Courses: the other quite large group is in their final year of high school, and has not attained the Texas College Readiness Standard ${ }^{2}$ despite having completed the requisite academic coursework.

The connecting theme of the two populations is that they have successfully completed high school course work that is not reflected in their performance on standardized tests and placement exams. Anecdotal conversations with students indicate that they have seen the material covered in the classes on their transcript (often recognizing terms) but they have taken little, and often no time, to practice the material and become comfortable with it. Both the small- and large-scale interventions have been designed to focus students on practice and mastery of the material, delivering course material with computer software, and using the teacher to provide one-on-one instruction that is individualized for the student and directed to the specific difficulties they are having.

In this paper we will first describe the design and results we have had for the first two cohorts of the Bridge to Calculus. We will then describe the course design and results of the first cohort of the College Preparatory Mathematics Course. There are large differences between these two interventions, and from the point of view of results, the most important difference is that with the College Preparatory Mathematics Courses, because the course was only designed by us, but is implemented by our partnering school districts, we do not have a complete picture of the data to describe our results.

\section{Bridge to Calculus - the Small-Scale Intervention}

Typically, more than half of first-year students majoring in engineering and computer science are placed into courses below Calculus. A fifth to a quarter of the students begin their studies in College Algebra. This places these students significantly behind in an engineering or computer science degree plan, and contributes to difficulties with retention in the majors and successful completion of the major. Students electing majors in mathematics and science are similarly 
affected. We find that a significant number of first-year students have Calculus courses appearing on their high school transcripts without corresponding credit for these courses through an AP-test or Dual Credit for the course. Many of these students will not even place into PreCalculus but instead be directed to start their mathematics sequence with College Algebra. It appears that their high school mathematics coursework has done little to address deficiencies in their mathematics performance. The goal of the small-scale intervention is to pilot a method for dealing with such students, making use of their prior experience, that could be adopted at the institutional level. Results for the first cohort have previously been reported in ${ }^{8-9}$.

The underlying goal of the Bridge to Calculus project is to develop an intervention that addresses the needs, and makes use of the strengths of students who have prior experience with advanced high school mathematics courses but without the accompanying performance on standardized and placement tests that demonstrates this experience. We have done this by designing a course that uses computer software to deliver an modified emporium model course that is partially selfguided and involves students spending significant portions of the course working on problems with help from the instructor available at the moment the student has feedback on a problem.

The intervention is designed as a specialized Pre-Calculus course taught using a modified emporium method. The material covered is chosen based on feedback and input from Calculus instructors. The topics covered include large portions of both the College Algebra and PreCalculus courses, and in addition includes a collection of engineering design challenges aimed at addressing students' motivation for mathematics coursework. The instructor has changed in the first two cohorts, but in each case was an experienced Pre-Calculus instructor who had also taught the modified emporium courses we used for developmental mathematics at UTRGV. The emporium model involves students using a computer program such as the Assessment and Learning in Knowledge Spaces (ALEKS) in a computer lab ${ }^{1,11-13}$. The students spend class time working on mathematics problems, receive immediate feedback on those problems, and have a chance to work with the instructor to address the specific problem they have encountered and have their deficiency addressed. This method of instruction adapts the course to individual students, allows students to move at their own pace, and gives students a chance to practice the course material in a setting that is plush with opportunities for feedback and assistance from: the software, fellow students, the instructor and course mentors ${ }^{14}$.

If successful in the course, a student will be Calculus ready for the fall semester of their firstyear. One of our struggles has been getting students who are successful in the program into a Calculus 1 class, in the Fall 2015 semester out of 22 students who successfully finished the summer program, 5 did not enroll in Calculus 1 for the Fall semester. This is both a logistical and advising problem that will need to be addressed in the future. Of those that have participated in the program we find a passing rate (ABC) of $55 \%$ compared to $49 \%$ for the two fall semester Calculus classes as a whole. Table 1 summarizes the grade distributions. Passing rates for the course have dropped below those for the general sections of Calculus 1 in the same semester, however as before we find that the differences are not statistically significant. Likewise, the GPA of the students is not significantly different from that of the whole population (precisely the probability that a group of 33 students from Calculus 1 would have a GPA of 1.66 or higher is more than $35 \%$ ). While a goal is to be producing students with a higher than expected degree of success in Calculus 1, we are producing students whose success in Calculus 1 is comparable to 
that of students who have placed into Calculus 1 via more traditional means (mainly coursework).

Table 1: Grade distribution in the Fall 2014 and Fall 2015 Calculus courses.

\begin{tabular}{lcccccccc}
\hline & A & B & C & D & DR/W & F & Total & \% ABC \\
\hline Fall 2014 Calculus 1 & 64 & 63 & 78 & 42 & 114 & 55 & 416 & $49 \%$ \\
$\begin{array}{l}\text { Summer Bridge Students } \\
\text { in Calculus 1 2014. }\end{array}$ & 1 & 4 & 5 & 3 & 2 & 1 & 16 & $63 \%$ \\
Fall 2015 Calculus 1 & 88 & 84 & 92 & 75 & 131 & 80 & 550 & $48 \%$ \\
$\begin{array}{l}\text { Summer Bridge Students } \\
\text { in Calculus 1 2015. }\end{array}$ & 3 & 2 & 3 & 2 & 6 & 1 & 17 & $47 \%$ \\
\hline
\end{tabular}

\section{Bridge to Calculus: Lessons Learned}

- Student Performance: As noted above students' performance has not improved significantly, and has even decreased, from that of students who have placed in Calculus 1 via more traditional means. There were instructor changes in our program and also in the Calculus course, and it is not clear where the cause of this change was. With the third cohort we will have sections of the project running in both of our campuses and with the increase in both numbers of students and the number of Calculus 1 sections they will enter, we hope to have more information about how we might improve students' performance in Calculus 1.

- Student Engagement: While we have had the majority of participating students complete the course, there have been some commonalities in the students who did not complete the program. In the first cohort, of the five students who were not successful (out of 22), we found that four had significant work commitments outside of class. In the second cohort we recommended that students with fulltime work commitments not participate.

- Student Participation: Student participation has been a strong positive. Between the two cohorts there have been only two absences and two tardies, a remarkable record that is atypical for mathematics courses at our university. The two absences were from students commuting to our campus from Mexico who were stuck in Mexico when the border was closed by the US government during our program. Requesting incoming Engineering and Computer Science students to volunteer for a summer course activity is an effective means of identifying motivated students who will take the course activities seriously.

- Advertising the Program: An additional difficulty with our program has been attracting a full cohort of 25 students. There is a reluctance among incoming students to participate 
in a summer course before their first full semester at the university. It now appears that we have come upon a method for finding a group of highly motivated students, by asking them to participate in this summer activity we end up with students who will take our course activities seriously and work diligently to complete the goals. This information will be useful for future iterations of this and similar projects targeting incoming students.

\section{College Prep Mathematics Course - The Large-Scale Intervention}

We also find that large numbers of students entering the university place into courses below College Algebra (remedial or developmental courses) ${ }^{10}$. These courses place significant burdens on students, that often will preclude them from considering a major in engineering or computer science regardless of their interest or motivation. The contradiction is that this group of students at UTRGV have passed their high school mathematics courses that cover the state's college readiness standards ${ }^{2}$. The goal of the large-scale intervention is an intervention that can be implemented for high school seniors, a strategy that was made possible by recent legislation in Texas.

In 2013, the Texas state legislature passed an act commonly known as House Bill 5 that included a number of significant changes to the state educational code affecting public school districts at the high school level: the creation of Endorsement Categories and requiring that school districts partner with a state institution of higher education to develop College Preparatory Courses in mathematics and English language arts ${ }^{15}$. These courses would earn successful students a temporary waiver from the Texas College and Career Readiness standardized assessment (a modified version of the commonly used Accuplacer test). Successful students would be qualified for entry level college courses in mathematics, science, and other subjects. Throughout much of the state the response to this legislation took the form of individual school districts partnering with a community college and developing a course for the district high schools. The typical mathematics course created mimicked what was being done for developmental education at most of the colleges in the state, including requiring the purchasing of textbook and software materials.

In 2014 UTRGV joined a consortium of the 2-year colleges (South Texas College, Texas Southmost College, Texas State Technical College in Harlingen) and our 4-year university, a local collective impact non-profit (RGV Focus), and the Region One Texas State Education Service Center to develop the College Prep Course for the four counties served by our schools. Representatives of the institutions of higher education gathered to develop the courses.

The College Preparatory Mathematics Course does not explicitly target engineering or computer science students. Students who place into entry level college courses save money and time over students that are required to take remediation efforts. Being required to take these courses would preclude most students from even attempting an engineering and computer science major regardless of additional expertise, experience or motivation.

The aim of the course is to work with students who have taken the high school mathematics courses that cover all of the material in the state college and career readiness standards, but who are not obtaining proficiency in those standards on the common state assessment test ${ }^{2}$. At the institutions of higher education it has been determined through a sequence of course 
developments (independently conducted at each participating institution of higher education) that what is needed most for students in this category is a course design that emphasizes practice and mastery over lecture delivery of the material, in short an emporium mode ${ }^{14}$ as we designed for the Bridge to Calculus effort. Using software to deliver the course is an efficient and successful method of implementing this principle. Students receive immediate feedback on problems; and as they are in the classroom when they receive this feedback, the teacher engages with them at the moment when it is most beneficial.

The four counties served by our consortium are some of the poorest in the state $e^{4-7}$, any additional cost that this course placed on partnering school districts would limit the ability for the project to be widely adopted. In truth, this is likely true for most public school districts in Texas. Our goal was to create a course for the public school districts that would be sustainable and lead to other institutional efforts to improve the college readiness of students, and ultimately to a broader discussion than just preparing students for entry level courses, to that of improving the overall placement of students into the spectrum of mathematics courses offered by the 2-year and 4-year colleges and universities. With this in mind, we elected to make available to the school districts in the four county region the WebWork server that has been in operation at our university since 2002 for any high school mathematics course, and in particular for it to be the central component of our College Preparatory Course.

WebWork is a software initially created by a grant from the National Science Foundation through the University of Rochester in Rochester, New York. The software was originally written to be an online homework software for Calculus classes. The software is currently supported by the Mathematical Association of America, including with research into its usefulness in the mathematics classroom. Studies indicate that the system improves student persistence with homework in their classes over more traditional means of assigning and collecting student work: students using the system are more likely to attempt every problem on an assignment, and are more likely to seek help when confronted with a problem they can't solve $^{3}$. For our purposes the important feature is that as we run our own server, our university can make this software available to high schools in the region we serve for no cost.

The disadvantage of WebWork for our proposed course design is that unlike ALEKS it is not an adaptive system, or more precisely, if it will accommodate individual student's needs it will only be because of the direct input of the instructor into the system. This is in contrast to ALEKS where the system will adapt to the students' situation without constant input from the instructor. The instructors are high school teachers from the partnering school districts, none of whom had experience with this software before seeing our course design. So much of our support of the course takes the form of professional development working with the high school instructors on learning to use the software in implementing a modified emporium design course. In practice the amount of use made of the software will depend on the technology available at the high school, however overall, we have found the high school teachers have been looking for online problem software and are excited to use it for this course. We elected to allow partnering high schools to host other mathematics courses on our server.

The actual topics covered in our course are roughly the syllabi of high school Algebra 1 and a portion of Algebra 2 in our state, which it is important to recognize that participating students have already completed successfully. The topics chosen reflected the concepts included in the 
mathematics portion of the state's college readiness standards ${ }^{2}$; and the degree of emphasis placed on them, and rigor expected from the student is governed by the content on the state's college readiness assessment.

\section{College Prep Mathematics Course: Results}

We ran the first cohort in the AY2014-2015 school year. Trainings were provided to 60 high school teachers from the region, they were provided with a template course in WebWork and we demonstrated that it could be flexible enough to accommodate the particulars of available technology on their high school campuses. By the conclusion of the school year we had 70 high schools registered in our system, 25 of which were actively using the WebWork software in their course; we defined an active user as a teacher who elected to use the software to deliver the final exam for the course. The number of students registered in our system topped out at over 600 (though again not all were active) for the College Preparatory Mathematics Courses; and was above 700 including the other high school courses we hosted (College Algebra, Pre-Calculus, and AP Calculus). In AY2015-2016 the number of high schools participating declined to 47, as schools settled into understanding what their student demand was for the course, but the proportion of active users is higher, the number of enrolled students is down to just over 500 (again not all are active). The lists of high school courses we set up is available $\mathrm{e}^{16-17}$.

The greatest success we identified in the first cohort was large numbers of students passing the state's college readiness standard assessment after completing the first half of the curriculum. Our opinion is that this is likely partially due to the course design's emphasis on practice, and to the presence of a chapter of the first half of the curriculum focusing on number sense questions without a calculator. Certainly the dedication and hard work of participating teachers in adapting to the course goals and using the resources provided was a key contributor to this success as well. Unfortunately, the precise numbers are not available because our project was relying on the voluntary reporting from participating school districts; however, after surveying participating teachers, it appears that more than a third of the students in the first cohort became college ready before the class was completed. In the second cohort (AY2015-2016) this trend has continued with a large portion of the successful fall class passing the state assessment.

Those who did not achieve the college readiness standard on the state assessment were eligible for a waiver to the college readiness standard at the participating 2-year and 4-year institutions if they successfully complete the entire course and passed the final assessment we delivered to their teachers, which was graded by the teachers. We do not know the precise number of waivers as reporting by the school districts was voluntary; however, we do know how many waivers were used at the participating institutions. The 2-year institutions accepted a total 150 students who used waivers for mathematics or English, or both; and our 4-year university accepted 53 students who used waivers for mathematics or English, or both. So neglecting the English courses for now, we see that there were a maximum of 203 waivers in the region used from our course, indicating roughly another third of the class obtaining this success.

Despite the difficulties with data collection arising from the size and scope of the project, we have seen some positive outcomes from participating students. Most importantly success on the state's college readiness assessment is a clear indicator that our course has improved students' performance on this standardized test. 


\section{Future Work}

The two projects discussed here, a Bridge to Calculus and the College Preparatory

Mathematics Courses, are connected by the common thread of working with groups of students who are repeating mathematics material for a second or third time, and with students who are possibly being hampered by a test anxiety. The course design in both small-scale and large-scale implementations, of a modified emporium model using computer software to emphasize practice and mastery is showing a number of signs of success with this type of population. The proposal for future development is to use this course design to address students who are repeating college level courses for a second or third time and to broaden the efforts at improving students' initial mathematics placement.

High school mathematics in Texas emphasizes the use of technology such as calculators, which is an important skill and can serve an important function in improving students understanding and multiple view points on the problems they are learning. However, underperforming students are prone to losing skills in dealing with fractions and decimals without a calculator. It appears that this can affect their ability to demonstrate their understanding of more advanced mathematics topics, especially as the use of a calculator on the state's college readiness assessment is controlled. We have found that giving these students a short lesson in reviewing this basic mathematics skill, has a large impact on their performance on standardized tests and assessments that we use for placement purposes. The evidence for this is the success we are having in the first half of our College Prep Course.

Finally, cost is an important feature of projects that are meant to eventually be brought to a multiple county scale for potentially one thousand or more students. The small-scale project, meant as a pilot to address students' placement into Calculus, was part of a funded project and it was natural to explore the use of commercial software in that. As we work on bringing that effort to a wider audience it is important that we consider the potential cost savings of a software such as WebWork. Accordingly, in the third cohort of the Bridge to Calculus we will conduct the intervention using WebWork as a study of its possible usefulness in scaling the project up to meet the needs of all incoming Freshmen placing below their high school experience at a cost free advantage for the students.

For the high school course the use of commercial software was never an option, and so we are entering on a five-year sequence of course development to refine this project and solidify the curriculum while maintain our zero cost. Two important developments are arising in the near future:

- We plan to implement a truncated version of the curriculum suitable for a high school to use as a workshop rather than a full year-long course. This workshop would be aimed at improving students' scores on the state assessment of college readiness.

- We plan to develop a version of our course that could be used by students who are in career paths, which will not require College Algebra, such as nursing. 


\section{Acknowledgements}

The authors would like to thank the Division of Undergraduate Education at the National Science Foundation for its support through the STEP, "Graduate $10 \mathrm{~K}+$," initiative under grant number NSF-DUE 1317661, which funded the Bridge to Calculus.

The authors need to thank a number of people from the 2-year, 4-year, high school, state educational service center, and local non-profits who were involved in the large-scale College Preparatory Mathematics Course: Enrique Arredondo and Pablo Cortez (STC), Michael Murphy (TSTC), Abraham Jimenez (TSC), and Luis Sanchez and Dambru Bhatta (UTRGV) served on the development team for the course; Thane Stroop (Edinburg CISD), Enrique Linan (San Benito ISD), Martha Ocanas (Weslaco ISD), Rene Acevedo (Mission ISD), Manuel Rodriguez (La Joya ISD), and Emilio Mendez (Hidalgo ISD) were high school teachers who coauthored the WebWork template we used in the second cohort, Abraham Jimenez (TSC) and Luis Sanchez (UTRGV) were also co-authors of the template; John Montablo was a graduate student in mathematics at UTRGV who provided computer programing expertise to the project for the first cohort and also co-authored the WebWork template used in the second cohort; Nicole Saenz (ESC-1) has provided logistical help for the professional development; Luzelma Canales and her colleagues at RGV Focus took the lead in assembling the collaborators.

\section{References}

1 Assessment and Learning in Knowledge Spaces, https://www.aleks.com/, McGraw Hill.

2 Texas College and Career Readiness Standard, http://www.thecb.state.tx.us/collegereadiness/crs.pdf

3 WebWork Homework Software, http://webwork.maa.org/, Mathematical Association of America. Census Quick Facts Report for Hidalgo County, http://www.census.gov/quickfacts/table/PST045215/48215 Census Quick Facts Report for Cameron County, http://www.census.gov/quickfacts/table/PST045215/48061

6 Census Quick Facts Report for Starr County, http://www.census.gov/quickfacts/table/PST045215/48427

7 Census Quick Facts Report for Willacy County, http://www.census.gov/quickfacts/table/PST045215/48489

8 Virgil Pierce and Javier Kypuros (2015). A Summer Bridge to Calculus for Students in Rio South Texas. ASEE Annual Conference. Seattle, WA.

9 Virgil Pierce and Javier Kypuros (2015). A Summer Bridge to Calculus in Rio South Texas using an Emporium Method. Frontiers in Education 2015. El Paso, TX.

10 Report on Fall 2014 placement at the University of Texas - Pan American (which became the Edinburg campus of UTRGV in September 2015) below College Algebra from the Texas Higher Education Coordinating Board, http://www.txhighereddata.org/reports/performance/deved/inst.cfm?inst=003599\&report_type=4\&report_y $\mathrm{r}=2015$

11 Doignon, J.-P., Falmagne, J.-C., Learning Spaces. (2011) Springer-Verlag.

12 Doignon, J.-P., Falmagne, J.-C., Knowledge Spaces. (1999) Springer-Verlag.

13 Falmagne, J.-C., Koppen, M., Villano, M., Doignon, J.-P., Johannesen, L. "Introduction to knowledge spaces: How to build, test, and search them." Pschological Review, 97, (1990): 201-224.

14 Twigg, C. "The Math Emporium: Higher Education's Silver Bullet." Change: The Magazine of Higher Learning, May-June (2011).

15 Text of House Bill 5 of the $83^{\text {rd }}$ session of the Texas legislature, http://www.capitol.state.tx.us/tlodocs/83R/billtext/pdf/HB00005F.pdf\#navpanes $=0$

16 UTRGV WebWork HS Course List AY2014-2015, https://webwork.utpa.edu/CollegPrep-2014-2015.html

17 UTRGV WebWork HS Course List AY2015-2016, https://webwork.utpa.edu/CollegPrep-2015-2016.html 


\section{Virgil U. Pierce}

Dr. Pierce earned a PhD in Mathematics from the University of Arizona in 2004, and joined the faculty of UTRGV (then UTPA) in 2008 after a postdocs at Brandeis University and Ohio State University. In 2014 he was awarded the University of Texas System Board of Regents' Outstanding Teacher Award in recognition of his commitment to excellent teaching and to broadening the access and success of higher education to the residents of Texas. He is currently serving as the Associate Dean for Undergraduate Education in the College of Sciences at UTRGV.

\section{Javier A. Kypuros}

Javier Kypuros received a B.S.E. in Mechanical Engineering from Princeton University in 1996. He later received an M.S.E. and Ph.D. in Mechanical Engineering in 1998 and 2001 from The University of Texas at Austin. Javier began his career at The University of Texas at El Paso in 2001 and later joined the faculty at The University of Texas-Pan American (UTPA) in 2002. He is currently a Professor in the Mechanical Engineering Department and Associate Dean for Undergraduate Affairs in the College of Engineering and Computer Science. He was awarded Faculty Excellence Awards by the College of Engineering and Computer Science at UTPA for teaching in 2011 and service in 2012 and was recognized by the University of Texas System with a Regentss Outstanding Teaching Award in 2014. His research interests include Dynamic Systems and Controls, Bond Graphs, and Vehicle Systems.

\section{Shirley Mills}

Shirley Mills is an associate professor in the Department of Organization and School Leadership. Prior to earning a Ph.D. in Educational Leadership and Higher Education at the University of Nebraska-Lincoln in 2005, she was an elementary and English language arts teacher. In 1995, she won a National Presidential Award for Excellence in Science and Mathematics Teaching. Currently, Dr. Mills is the Director of College Readiness Initiatives and serves as the coordinator for the AVATAR and Pathways Projects, both of which promote vertical alignment of K-12 and higher education curriculum in Region 1. 